\title{
Serum screening for Down's syndrome: some women's experiences
}

\author{
Helen Statham, Josephine Green
}

\begin{abstract}
Objectives-To describe the experiences of a small group of women who had positive results after serum screening for Down's syndrome.

Design-Semistructured telephone interviews and correspondence with women after a positive screening result (four women) negative amniocentesis results (eight), or termination of a pregnancy with a confirmed abnormality (eight).

Subjects-20 women who contacted Support After Termination For Abnormality about their experiences of serum screening for Down's syndrome.
\end{abstract}

Main outcome measures-Women's knowledge and understanding of the test; staff misconceptions; communication of results; how women coped with the diagnostic process; attitudes to the test and to termination of abnormal fetuses.

Results-All women were made anxious by their positive screening test, no matter how they were told. The women's experiences suggested that medical staff were unclear about the implications of screening tests and how to interpret risk. Even after receipt of negative amniocentesis results some women remained anxious. Staff did not always recognise women's concerns while awaiting amniocentesis results.

Conclusions-The way in which serum screening is being implemented does not always meet the needs of women with positive results. Some of the problems were not specific to screening for Down's syndrome. When screening tests are introduced policies should be adopted to ensure appropriate support for participants.

\section{Introduction}

Serum screening for Down's syndrome has been introduced in several districts in Britain. ${ }^{1}$ There has been much discussion about biochemical and statistical parameters ${ }^{2-4}$ but little evaluation of psychological and social aspects. ${ }^{5}$ We present the experiences of a sample of British women who had positive results on screening for Down's syndrome.

\section{Subjects and methods}

We studied 20 women who had contacted Support After Termination For Abnormality (SATFA) after serum screening. Eight women had negative amniocentesis results, two did not have amniocentesis, and eight women terminated pregnancies with confirmed abnormalities; amniocentesis results were not known in two cases.

Semistructured telephone interviews were conducted by HS in mid-1992. We obtained additional information by letters in four cases and in face to face discussion in another four. The women were aged 20 to 44 and had a risk of Down's syndrome of $1: 2$ to $1: 250$.
Results

KNOWLEDGE AND UNDERSTANDING BEFORE TEST

The five women who asked for the test said that they felt well informed. But some women who had had the test routinely had not known that it screened for Down's syndrome. One woman did not read the information sheet she was given, assuming it to be about screening for spina bifida. One woman believed she was informed when she had the test but "when the news came that I had a 1 in 20 chance of having a Down's syndrome baby, we realised we knew nothing."

\section{STAFF MISCONCEPTIONS}

A 40 year old woman who had had a previous pregnancy affected by Down's syndrome was unable to convince a midwife that the test was inappropriate after her negative result on the chorionic villus test. Staff seemed to have poor conceptions about risk, resulting in suggestions to a woman with a 1 in 16 risk to "have no hope" and to others that their risk could be explained away because the test is "unreliable." One woman had a two week delay between a positive screening result (risk 1 in 10) and a hospital appointment because her general practitioner thought the result meant that her dates needed checking. She said that this delay "used up a lot of my resources for coping." Another was told by her general practitioner that: "it wasn't worth coming for any antenatal visits until I knew it was okay."

\section{COMMUNICATION OF RESULTS}

All of the women said they were anxious once they realised they were being told that their risk of Down's syndrome was high and warranted further discussion. They became anxious whether told by a midwife who had visited them at home, by telephone at home or work, or in a hospital consultation. A woman recalled to discuss possible dating problems said she would have liked warning that "the misleading" results might mean a high risk of Down's syndrome ( 1 in 8 ) so that she could have taken someone with her.

\section{COPING WITH SCREEN POSITIVE RESULTS}

At least eight women had difficulty in applying a " 1 in something" risk to their own pregnancy and the woman who had had chorion villus sampling was panicked by her 1 in 35 risk, even though she knew she already had Down's syndrome excluded. While the way in which women were given positive results apparently had little impact on their distress, the subsequent behaviour and attitudes of health professionals seemed to be important in determining how women coped while waiting for amniocentesis and its results. Eight women spoke of staff being very understanding and of not feeling rushed or pressurised to have or not have amniocentesis. Others felt less supported. One spent a weekend in shock awaiting amniocentesis, with no one available to give her the information she needed after being told she had a 1 in 
20 risk of an affected pregnancy on a Friday afternoon. Others felt pressurised to make the decision to have amniocentesis quickly without full information. When midwives and staff made themselves and other sources of information and support available, this was welcomed.

\section{ULTRASOUND SCANS}

All women were scanned at the time of their amniocentesis, but three also had detailed scanning. For one, the discovery of heart abnormalities on the scan gave her time to prepare for the almost inevitable amniocentesis result. Although the women recognised that normal scan results did not necessarily mean a normal baby, they were still reassured by the absence of physical abnormalities. One said "It was my decision to have the termination and screening tests, but not the scan that was advised and booked for me. They made that decision; it was a mistake. I cannot even gain comfort from the knowledge that my baby had known physical abnormalities, I was simply able to see her, reinforcing the love before they told me my love was for the wrong baby."

\section{AMNIOCENTESIS RESULTS}

Women found waiting for amniocentesis results after a positive screening result stressful, particularly when results were imminent. Waiting for a telephone call was reported to be particularly stressful, but even those given specific appointment times often feared they would receive bad news earlier. One woman was told she would be given results only if they were positive.

Women given positive diagnoses all made the difficult decision to terminate the pregnancy. The hospital care was generally appropriate with the parents' perinatal bereavement being acknowledged.

Although women given negative results reported enormous relief initially, worries often re-emerged later. Some were concerned about the initial result: "if the baby doesn't have Down's syndrome, what does it have?" One woman who had been "totally reassured" by amniocentesis said that as soon as the baby was born she asked for a paediatrician to check immediately for Down's syndrome. One woman had been convinced that the amniocentesis would show Down's syndrome and the negative result left her feeling guilty about her baby being healthy.

\section{ATTITUDES TO THE TEST AND TERMINATION}

Women thought that testing should be available for fetal abnormality in general and serum screening was a welcome addition to previously available tests. Three women had tried to avoid amniocentesis and younger women were reassured to have had amniocentesis. Nine women said they would take similar courses of action in subsequent pregnancies, although two of the older women said they might choose amniocentesis directly. Three women were still trying to explain their positive test result and were invoking fertility treatment, extreme nausea, and genes. Two of those with negative amniocentesis results felt they had been "lucky" that they had been very close to having a Down's baby.

All 20 women believed it was right to be able to have a termination for abnormality, although one said that until the amniocentesis result arrived (negative) she and her partner had not decided what they would do. Those who terminated affected pregnancies found it difficult. One of the women, who taught adults with Down's syndrome, wrote: "I didn't want to give up my baby, yet I had to because I knew what the future held for all of us if I kept hold of her." One woman chose termination only because physical anomalies had been found. Only one woman expressed any doubts:

\section{Practice implications}

- Serum screening for Down's syndrome is increasingly offered to pregnant women in Britain

- All screening tests produce a proportion of false positive results

- Women who were told that they had an increased risk of having an affected pregnancy became very anxious

- Health professionals must recognise women's fears that their unborn baby might have a serious abnormality and their need for information about the implications of such a diagnosis

- Protocols concerning the implementation of screening programmes should include adequate psychosocial support for participants

"If they'd handed her to me and said she was Down's I'd have been upset but I'd have got on with it; but once you've got into the testing trap you have to get to the end." She said she would go through the tests in a subsequent pregnancy because it would be unfair on the baby who was terminated to proceed with another Down's pregnancy.

\section{Discussion}

The issues raised in this study of a selected group of women indicate three questions which a social evaluation of screening should address: should there be prenatal testing for Down's syndrome? If so, is serum screening a good enough test? If it is, how should the test be implemented?

Most pregnant women want to know if there is something wrong with their baby ${ }^{6}$ and so want screening to be available. The better informed women are, the higher the uptake of prenatal testing. ${ }^{7}$ There is still no consensus about whether serum screening is a good enough test when judged on biochemical, statistical, and financial parameters, ${ }^{2.489}$ but many pregnant women have decided the test is adequate for them. This could be because women have a poor understanding of the difference between screening and diagnosis.

\section{DEALING WITH FAISE RESUITS}

All screening tests give false positive and false negative results, and it is how these are handled that presents the greatest challenge. This was the important aspect for women in this study. Their fears were often not recognised; they were told that something was sufficiently worrying to warrant an invasive procedure with a risk of miscarriage, and then told to go away and not worry.

Lack of acknowledgement meant that there was no discussion of what would happen if Down's syndrome was diagnosed. "I tried to talk about a termination and how it would be done but the nurses just wouldn't talk about it. They said to make up my mind when I knew the results. I needed all the information to make my decision before." This was why some women contacted Support After Termination For Abnormality and also the Down's Syndrome Association. One woman said: "I've learnt a lot about how totally unprepared the medical services are at a local level for the abnormal result; they are lulled into a sense of security that the tests will give comfort." Yet screening tests have been part of routine antenatal care for many years and a literature exists concerning women's experiences of these. ${ }^{10}$ 
DEALING WITH POSITIVE RESULTS

Only women who had positive results were included in this study and the group may not even be representative of those with positive results since the women all contacted Support After Termination For Abnormality. This might indicate that they were particularly anxious. Positive screening results are known to generate anxiety ${ }^{611} 12$ and women recruited to a Dutch study expressed similar feelings to those described above, ${ }^{13}$ suggesting that these feelings may be widely experienced.

Women must be given information to enable them to make an informed decision about whether to have testing, ${ }^{514}$ but we cannot assume such information will reduce the anxiety caused when a result is positive.

Availability of good information and attitudes of staff to women with positive results are important as with any screening test. Protocols need to be drawn up to ensure that those who have positive screening results are given appropriate support to enable them to cope with their distress.

^Support After Termination For Abnormality is a registered charity which supports parents who have fetal abnormalities diagnosed. As well as giving direct support to parents, SATFA works with health professionals involved at the time of diagnosis, termination, and afterwards to encourage a greater understanding of parents' needs, to promote good practice, and to recognise the support needed by staff. SATFA can be contacted at 29-30 Soho Square, London W1V 6JB (tel 0712873753 ).

1 Wald N, Wald J, Smith D. The extent of Down's syndrome screening in Britain in 1991. Lancet 1992;340:494.

2 Wald NJ, Kennard A, Densem JW, Cuckle HS, Chard T, Butler L. Antenatal matermal serum screening for Down's syndrome: results of a demonstration project. BM7 1992;305:391-4.

3 Spencer K. Antenatal screening for Down's syndrome. BMF 1992;305:769.

Cuckle HS, Wald NJ, Barkai G, Fuhrmann W, Altland K, Brambati B, et al. First trimester biochemical screening for Down syndrome. Lancet 1988;ii: 851-2.

5 Clarke A, Parsons EP. Screening, ethics, and the law. BMF 1993;306:209.

6 Green J, Statham H, Snowdon C. Pregnancy: a testing time. Report of the Cambridge prenatal screening study. Cambridge: Centre for Family Research, University of Cambridge, 1993.

7 Marteau TM, Johnston M, Shaw RW, Slack J. Factors influencing the uptake of screening for open neural-tube defects and amniocentesis to test for Down's syndrome. Br J Obstet Gynaecol 1989;96:739-42.

8 Sheldon TA, Simpson J. Appraisal of a new scheme for prenatal screening for Down's syndrome. BMF 1991;302:1133-6.

9 Keatinge RM, Williams ES. Prenatal screening for Down's syndrome. BMf 1991;303:54

10 Green J. Calming or Harming? A critical review of psychological effects of fetal diagnosis on pregnant women. London: Galton Institute, 1990. (Occasional papers, second series, No 2.)

11 Farrant W. Stress after amniocentesis for high serum alpha-fetoprotein concentrations. $B M \mathcal{F}$ 1980;281:452.

12 Marteau TM, Kidd J, Cook R, Johnston M, Michie S, Shaw RW, et al. Screening for Down's syndrome. BMF 1988;297:1469.

13 Roelofsen EEC, Kamerbeek LI, Tymstra T. Chances and choices: psychosocial consequences of maternal serum screening. A report from the Netherlands. Joumal of Reproductive and Infant Psychology 1993:11:41-7.

14 Marteau TM. Screening, ethics and the law. BMf 1992;305:1434.

(Accepted 17 May 1993)

\section{A MEMORABLE PATIENT}

\section{Like father like son}

$M$ was 46 years old and fat. He was a stressed, hypertensive, heavy smoking teacher and was married with two sons. While teaching one day, he suddenly developed a feeling of apprehension of sufficient significance for him to tell the headmaster he was going home. While driving past the local district general hospital he noticed that his right foot was cold and numb and so he drove into the casualty department.

On examination his right foot was noted to be ischaemic. $\mathrm{He}$ was seen by the surgical registrar and embolectomy was arranged. A Foggarty catheter was passed down the femoral artery, and, although no thrombus was found, flow was restored. He was nursed on the intensive care unit. Chest $x$ ray examinations on the subsequent two days showed widening of the mediastinum, and a soft early diastolic murmur confirmed the likely diagnosis of dissecting aortic aneurysm. He was referred to the cardiothoracic unit, where an arch aortogram showed a dissection extending from the aortic root to the right iliac and femoral arteries. All major branches had been preserved. He was by then asymptomatic. It was decided that the dissection was too extensive for repair, and conservative treatment was recommended.

$\mathrm{M}$ was one of those rare people who can successfully change behaviour and lifestyle. He stopped smoking. A vegetarian diet and cycling restored him to a normal body mass index. He resigned from his teaching career and concentrated on his other interest of painting. He became fit, slim, healthy, relaxed, and happy with it.

$\mathrm{He}$ still had mild aortic regurgitation and after two years, although he was not keen, I referred him to a further cardiothoracic unit for consideration for elective aortic arch replacement. He was put on the waiting list.
His turn came at a most inconvenient time-he had just demolished the back of his house and was building a kitchen extension. Not wishing to seem ungrateful he asked that I contact the surgeons to explain. This done, it was agreed that we would make contact when it was convenient. Eight years passed, not only of inconveniences, as he was always busy with some essential activity, but also of much philosophising as to whether, anyway, it was the right course of action. We both in the end agreed to continue a conservative policy.

Latterly, his 22 year old son was at a party and suddenly had a feeling of apprehension. He left the party and attended a local casualty department. No abnormality was found, and he was allowed home. He couldn't go home, however, as $M$ and his wife were also at a party, so he went to his grandmother's house. Shortly after arrival he collapsed and died. His grandmother telephoned the police, who contacted $M$ and his wife but, as instructed, did not tell them the reason. On arrival at the house and on hearing the tragic news $M$ also collapsed and died. A necropsy showed him to have died, as also had his son, from a ruptured dissecting aortic aneurysm.

I shall always remember this dramatic tale, and I still remain unsure, despite many reassurances from colleagues, whether I was right to support $M$ in his wish to avoid surgery or whether, in medical audit terms, this should have been considered a serious adverse event.WILLIAM D ALEXANDER is a consultant physician in Sidcup, Kent

We welcome contributions to fillers: $A$ patient who changed my practice; $A$ paper that changed my practice; $A$ memorable patient; The message I would most like to leave behind, or similar topics. 